\title{
Influence of Surfactant Additives on Photochemical Synthesized Silver Nanoparticles using UV Pulsed Laser Irradiations in Aqueous Silver Nitrate Solution
}

\author{
Umair Yaqub Qazi
}

Department of Chemistry, College of Science, University of Hafr Al Batin. P.O Box 1803 Hafr Al Batin 39524, Kingdom of Saudi Arabia

Corresponding Author Email: umairqazi@uhb.edu.sa

\begin{abstract}
The effect of different additives on the AgNPs formation process was explored in this study. AgNPs were synthesized in an aqueous solution of silver nitrate-containing surfactants by photoreduction of silver ions. The concentration dependency of AgNPs formation suggested that stability was induced by the equilibrium of AgNPs adsorbed by surfactants with higher carbon chain molecules such as SDS and AOT. These results open up a new window both for structural control and the development process. It also indicated that different additives had an impact on the morphology of NPs. The hydrocarbon chain influenced the growth process and demonstrated that $<10$ carbon chain surfactants such as SMS, SOS, did not constitute the CGC and had a minor effect on the mechanism of growth. However, the NPs formation begun at a lower limit indicated as CGC. It was observed only with hydrocarbon chains of > 10 carbon atoms such as AOT, SDS. Fluorescence results confirmed that after laser irradiation, hemi-micelle formation after the development of AgNPs.
\end{abstract}

Keywords: Critical micelles concentration (CMC), Silver nanospheres (AgNSs), Laser irradiation, Nanotechnology, Critical growth concentration (CGC)

Received: January-06-2021, Accepted: April-25-2021, https://doi.org/10.14447/jnmes.v24i2.a07

\section{INTRODUCTION}

Nanotechnology was the most quickly developing field in global development, and nanomaterials were developed by modern, simple processes by researchers. Science has become popular over time in various fields, including materials science, electronics, and biotechnologies [1-12]. Nanoparticles are of considerable scientific importance in bridging the gap between bulk substances and atomic or molecular structures [13]. The metal nanoparticles are the most promising among different types of nanoparticles because of their antibacterial effects due to the high surface to volume ratio. The changes in the composition of size or surface can affect the physical and chemical characteristics of the nanoparticles [14, 15]. Metal nanoparticles have been used in many industries in recent decades due to their wide variety of applications [16-33]. The physical, chemical, and electrical properties of nanoparticles dramatically change at a specific size range $(1-100 \mathrm{~nm})$. These properties depend on the size and characteristics of metal nanoparticles, such as melting temperature, magnetic computability, redox potential, and color [34]. In recent years the use of silver nanoparticles in several fields, including the medical sciences, in order to cope with HIV viruses, infectious disease, the food processes as antibacterial agents in food packaging and antibacterial properties and as antibacterial agents in nutrient packing, has drawn attention to a strong conductiveness, chemical stability, and use as a catalytic agent [35-50]. Studies have shown that metal nanoparticles highly influence the bulk, morphology, stability, and (chemical and physical) properties of the experimental conditions, the Kinetics of metal ions interaction with reduced agents, and adsorption of metal nanoparticles by stabilizing agent [51-53]. In general, precise regulation of the structure, size, and distribution of the nanoparticles generated is accomplished with improvements in synthesis methods, reducing and stabilizing factors [54].

Adequately compensated chemical reductions, polyol, thermal decomposition, laser ablation and radiation, electron beam irradiation, and chemical in situ synthetic pathway, are currently the methods developed for synthesizing silver nanoparticles [6, 9, 51, 55]. Most recommended solutions are focused on the usage of chemicals such as metal ions reduction, conventional form of capping agents, and suspension maintenance stabilizers. The application prefers processes with fewer contaminants since these chemicals eventually need to be eliminated for NP synthesis. Instead of reducing agents, the photo-reduction approach was suggested to investigate the role of chemical additives in the NP formation process. Reducing agents may serve as capping agents that regulate the final shape of NPs, or capping agents and stabilizers may be chemically or photochemically oxidized and supporting the growth process by metal ion adsorption. It looks challenging to clarify the individual roles of the additional chemicals as long as we focus on those additives ${ }^{27}$.

In this article, we propose the use of UV irradiation for the reduction of silver nitrate aqueous solution. This study has presented us with a new methodology to produce standardized NPs with fewer additives. In addition, we can investigate the individual role for NP formation. This critical analysis has been documented in our previous studies with Sodium Dodecyl Sulfate (SDS) [56]. Silver nitrate has been dissolved in ultra-pure water like a silver salt precursor and prepared the 
necessary sample solution $\left(2 \times 10^{-4} \mathrm{M}\right)$. Researchers have implemented diverse approaches to synthesize NPs using surfactants [57]. AOT, SDS, and several other SMS, SOS additives have been added. Silver salt concentration remained constant in all experiments; however, the AOT concentration ranges from $3.5 \times 10-5-7 \times 10-4 \mathrm{M}$. AOT's (CMC value: $\left.1.4 \times 10^{-3} \mathrm{M}\right)[58]$. The molecular structure has 20 carbon atoms that make long hydrocarbon chains and a sulfate group connected to the middle. However, SDS (CMC value: $8.0 \times$ $\left.10^{-3} \mathrm{M}\right)$ [59] have 12 carbon chain. The specific molecular structure can have a specific influence on the development and size of the photo product. Focused on these points, thorough experiments were performed, and the results are presented. Herein, we investigated surfactant concentration dependence on AgNPs formation upon pulsed laser irradiation without reducing agents and found critical growing concentrations for surfactants. We utilized fluorescence probes to investigate structural changes in solution after nanoparticle formation.

\section{EXPERIMENTAL}

\subsection{Materials}

Silver nitrate was obtained from Sigma-Aldrich with 99.9 percent purity. Sodium bis (2-ethyl hexyl) sulfosuccinate (AOT), sodium dodecyl sulfate (SDS), sodium methyl sulfate (SMS), sodium octyl sulfate (SOS), and 9-diethylamino-5Hbenzo[ $\alpha]$ phenoxazine-5-one (Nile Red) were purchased from Wako Pure Chemicals, Co. Japan. Ultra-pure water (Millipore, $18 \mathrm{M} \Omega . \mathrm{cm}$ ) was used to prepare sample solutions.

Silver nitrate solution was kept in standard quartz cell $\left(10 \times 10 \times 45 \mathrm{~mm}^{3}\right)$ with a magnetic stirrer and irradiated (Quantel Brilliant, $355 \mathrm{~nm}$ wavelength, $6 \mathrm{~ns}$ pulse width, 300 $\mathrm{mJ} / \mathrm{cm}^{2}$ pulse, $10 \mathrm{~Hz}$ repetition) with UV-laser pulses. Silver nitrate was dissolved in ultra-pure water $(2 \times 10-4,1 \times 10-3 \mathrm{M})$ and irradiated with nanosecond laser pulses on a quartz cuvette without using a focus lens. After laser irradiation, a small portion of the solution was taken for the sample preparation and then observed in SEM, TEM. Figure 1 displays the schematic representation of the Experimental setup 1 for AgNPs synthesis by ns laser irradiation.

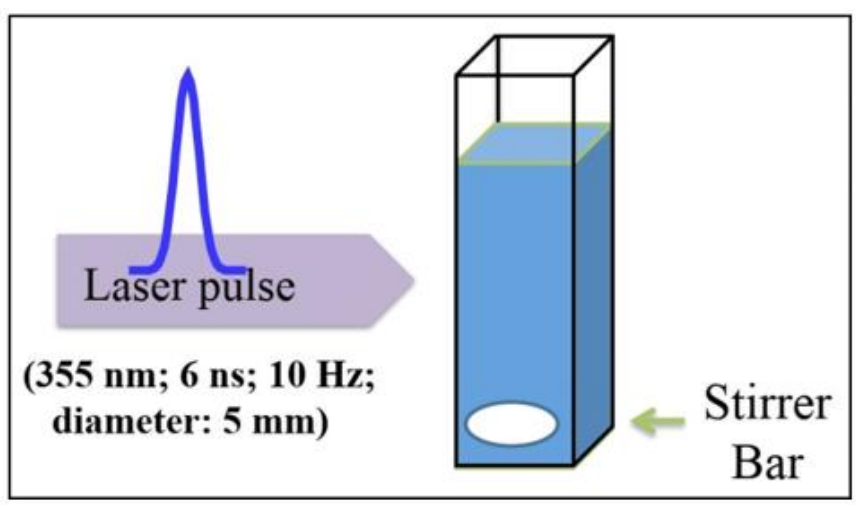

\subsection{Characterization techniques}

The UV-visible and fluorescence spectrophotometer Shimadzu UV-1600 was used for spectral recoding. The morphology and microstructure of the samples were studied by transmission electron microscopy using an acceleration voltage of $200 \mathrm{kV}$ (TEM). For SEM sample preparation, drop- casting photo reduced stock on ITO substrates, and drying in a desiccator is implemented. SEM images have been captured on Hitachi's FE-SEM-S4300 devices with $20.0 \mathrm{KV}$ to assess the shape and size of AgNP. To evaluate the size of the synthesized AgNPs, a high-performance digital light scattering (DLS) particle size analyzer was used by Malvern Instrument Co., MAL501088.

\section{RESULT AND DISCUSSION}

Silver nitrate was dissolved in ultrapure water with various amounts as a silver salt precursor. In this research paper, AOT, SDS, SOS, and SMS are added, and extensive experimental support is explored to expand our previous research results. The synthesized product morphology can be influenced by different molecular configurations and the carbon chain. The significant effect of these surfactants on the development of AgNPs is addressed.

\subsection{Optical properties and concentration effect of SDS}

Previously, photoproducts without using any additives were discussed in detail. A variety of products and their aggregates were formed without additives, including NCs with irradiation time. The addition of SDS markedly changed the photoproducts to homogeneous NSs with an average diameter of $14 \mathrm{~nm}$ (See S1 in supporting information). These results suggest that a variety of shapes, including NCs can be formed if silver atoms generated by photo-reduction of silver ions crystallize without any additives in the water, and SDS would be solely responsible for shaping NSs [56]. Figure 1 indicates the SDS concentration effect on the absorption spectra after pulsed laser irradiation. The increase in absorption peak position at constant silver nitrate concentration explains the growth rate, and the yield of AgNPs are SDS concentrationdependent. The lowest limit of the SDS concentration for AgNP formation was $\sim 5 \times 10^{-4} \mathrm{M}$, which is ten times lower than its CMC $(8 \times 10-4 \mathrm{M})$ [59]. It is not likely that SDS aggregates in solution work as a "template" of NSs. A particular concentration of SDS was required for silver nanoparticles formation. The lowest limit did not depend on the concentration of silver ions. The lowest limit, critical growing concentration (CGC), may be determined by a dynamic equilibrium between free SDS and SDS supporting AgNPs by adsorption [56].

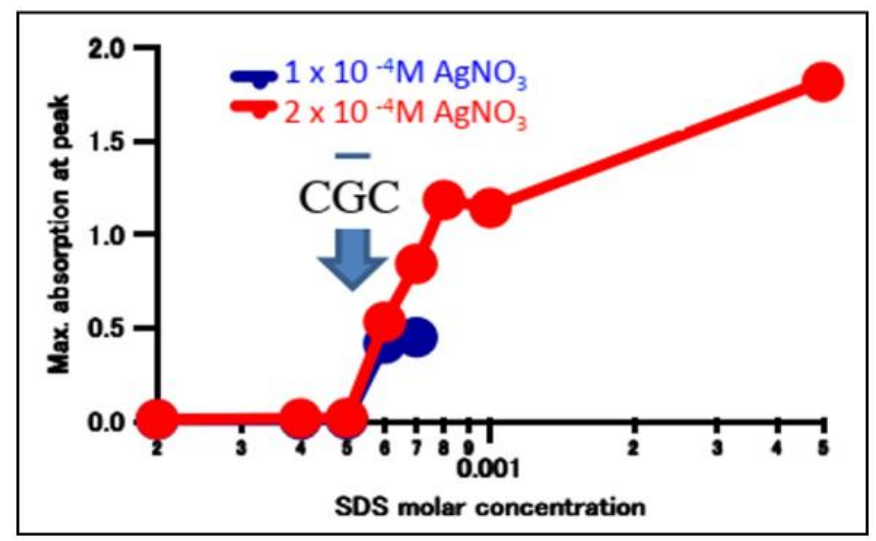

Figure 1. Maximum peak absorption after pulsed laser irradiation as functions of SDS concentration 


\subsection{Optical properties and concentration effect of Aerosol OT (AOT)]}

A surface plasmon absorption band at a peak position of 396 $\mathrm{nm}$ was observed, when silver nitrate solution containing AOT with different concentrations was irradiated with ns pulsed laser light. It indicated that absorption peak rosed over time, reached saturation, and then dropped down. Figure 2 displays absorption spectra at various concentrations of AOT along with corresponding peak positions. A small portion of the irradiated sample was used to investigate the photoproduct's morphology by TEM and DLS (See figure S2 in supporting information). It was confirmed that the average particle size was $8 \mathrm{~nm}$ and spherical. In the past, scientists have proclaimed that absorption peak at $395 \mathrm{~nm}$ corresponds with small spherical nanoparticles in the range of 1-10 nm [60-62]. Hence, AOT showed a similar trend, as observed in SDS. The CGC of AOT was $\sim 1 \times 10-4 \mathrm{M}$, which is ten times lower than its CMC $(\sim 1.4 \times 10-3 \mathrm{M})$.

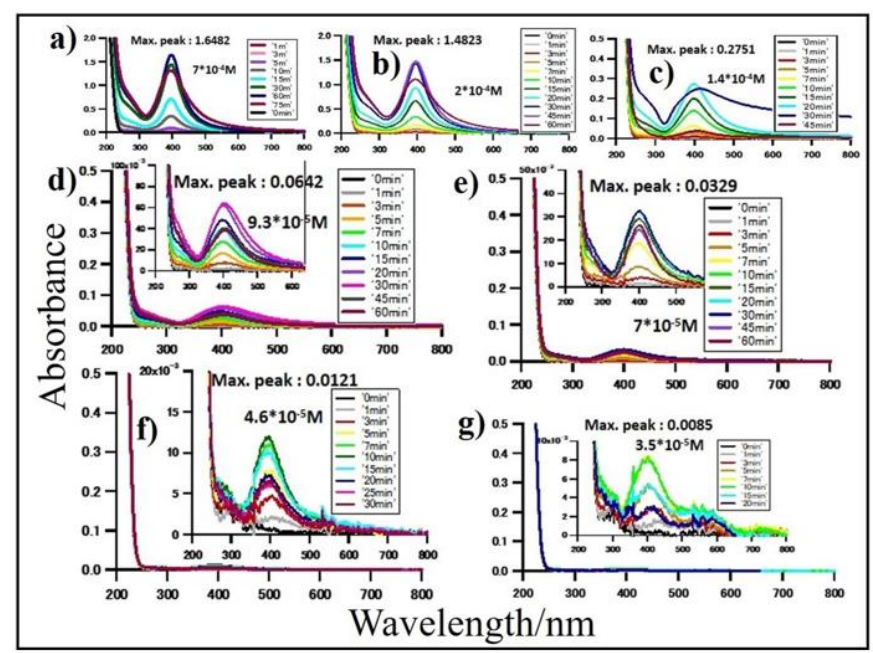

Figure 2. Showed maximum peak absorption after pulsed laser irradiation at constant silver nitrate concentration of $2 \times 10-4 \mathrm{M}$ while various AOT concentration as a) $7 \times 10-4 \mathrm{M}$ b) $2 \times 10-4 \mathrm{M} \mathrm{c}) 1.4 \times 10-4 \mathrm{M} \mathrm{d}) 9.3 \times 10-5 \mathrm{M}$ e) $7 \times 10-5 \mathrm{M} \mathrm{f}$ ) $4.6 \times 10-5 \mathrm{Mg}) 3.5 \times 10-5 \mathrm{M}$

\subsection{Optical properties and concentration effect of SOS and SMS}

In different SOS concentrations in aqueous solution, silver nitrate was irradiated at different times using ns pulsed laser light, and a surface plasm absorption strip was observed at 400-600 nm. It increased with time, reached saturation, and then decreased. Figure 3 provided the absorption spectra of AgNPs observed after different times of irradiation. Broad absorption spectra demonstrate that the AgNPs are spread in a wide variety of shapes and sizes. The absorption spectra also indicate an increase in photoproduct formation production as the amount of SOS increases. Enhanced AgNPs are indeed part of SOS concentration owing to the development of broader absorption peaks, and because of the addition of NPs, the irradiated sample solution was not stable. There is no support for the formation of AgNPs with shorter alkyl chain surfactants. The inset of Figure 3 displays a plot of the maximum yield of NPs as a function of SOS concentration. The CMC value of SOS is $139 \mathrm{M}$ [63]. The absorption peak was broader, and CGC was not evident with a shorter alkyl chain as observed in AOT and SDS. Based on these results, it was concluded that the hydrocarbon chain played a significant role in the formation process. In order to further validate, the influence of the hydrocarbon chain was incorporated into the production phase of various molecules with a short carbon chain.

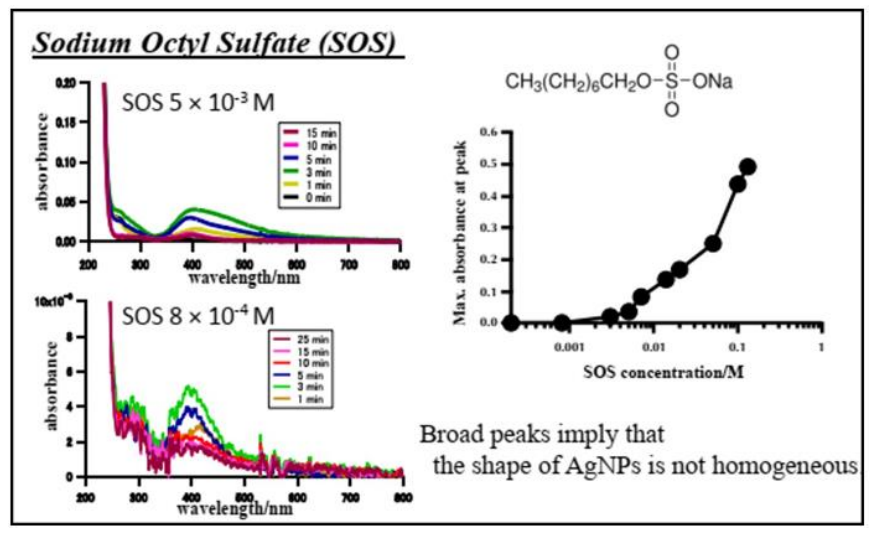

Figure 3. Absorbance spectra after laser irradiation (300 $\mathrm{mJ} / \mathrm{cm} 2$ ) with various concentrations of SOS; $5 \times 10-3 \mathrm{M}$ and $8 \times 10-4 \mathrm{M}$ while silver nitrate concentration kept constant ( $2 \times 10-4 \mathrm{M})$. Inset shows Maximum absorption as a funtion of SOS concentrations.

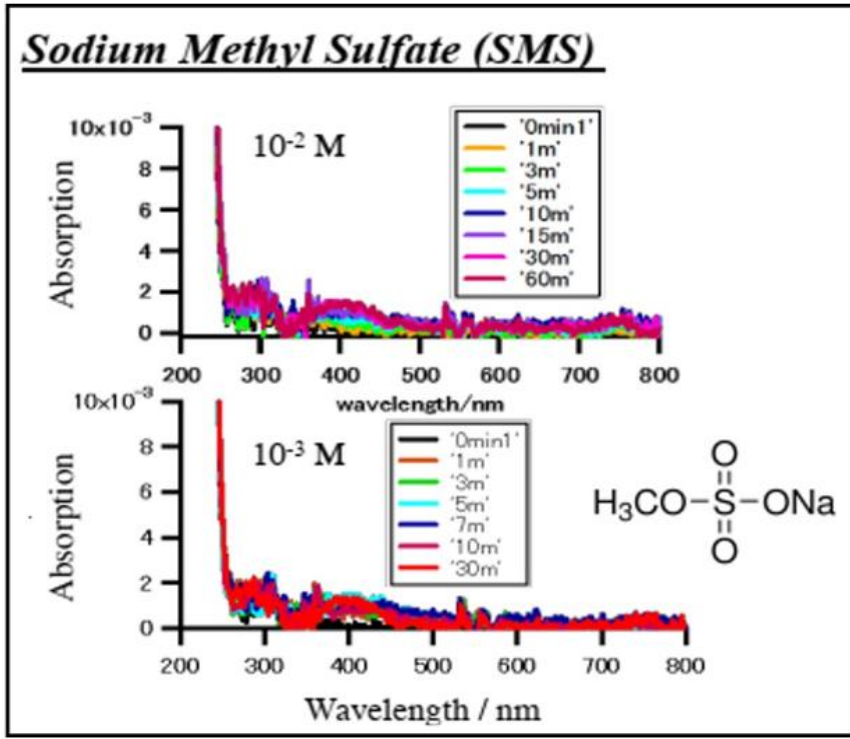

Figure 4. Absorbance spectra after laser irradiation (300 $\mathrm{mJ} / \mathrm{cm} 2$ ) with various concentrations of SMS; $10-3 \mathrm{M}$ and

10-2 $\mathrm{M}$ while silver nitrate concentration kept constant $(2 \times 10-4 \mathrm{M})$

Figure 4 shows the absorption spectra of SMS after laser irradiation. Sample solutions have been developed with different SMS concentrations $\left(10^{-3}\right.$ and $\left.10^{-2} \mathrm{M}\right)$ and irradiated with a pulsed laser having power $300 \mathrm{~mJ} / \mathrm{cm}^{2}$. Even at high concentrations o SMS, no significant improvement in absorption spectra was observed. It indicates that SMS does not participate in AgNPs' progress, and the absorption spectra appeared identical to silver nitrate absorption spectra.

\subsection{Hydrocarbon chain effect on AgNPs growth.}

We implemented different models of the same functional group with different carbon chains like SMS, SOS, SDS, and 
AOT to validate the effect of the hydrocarbon chain on the AgNPs yield. In particular, the SMS and the SOS effects were not as influential as they were when the sum of carbon atoms in the carbon chain was below 10. Based on previous studies on various additives, the hydrocarbon chain has been a significant factor influencing the photoproduct yield. Long carbon-chain molecules $(>10)$ as found in SDS and AOT were used to assist the AgNps growth process, and the lower number of carbon atoms $(<10)$ did not contain CGC. Therefore, the photoproduct yield does not affect.

\subsection{Surfactant effect studied by fluorescence probe, Nile Red}

Nile red is well known as a fluorescence probe [64]. In a polar solvent, Nile red is not fluorescent. The fluorescence intensity becomes high, and the emission peak shifts in a nonpolar environment, like in lipid and micelle. Figure 5a indicates the fluorescence peak variation spectra of Nile Red at an excitation wavelength of $540 \mathrm{~nm}$ with different SDS concentrations. In contrast, Figure $5 \mathrm{~b}$ indicates clear evidence for fluorescence peak position shift with changing SDS concentrations. It is concluded that with the higher concentration of SDS, the fluorescence peak moved to short wavelengths. The intensity of emission also became higher with higher SDS concentration. The detailed experimental procedure for the Nile Red setup is shown in Figure 6. After AgNP formation by pulsed laser irradiation, Nile red aqueous solution was added into the AgNP/SDS solution, and then fluorescence spectra were obtained.

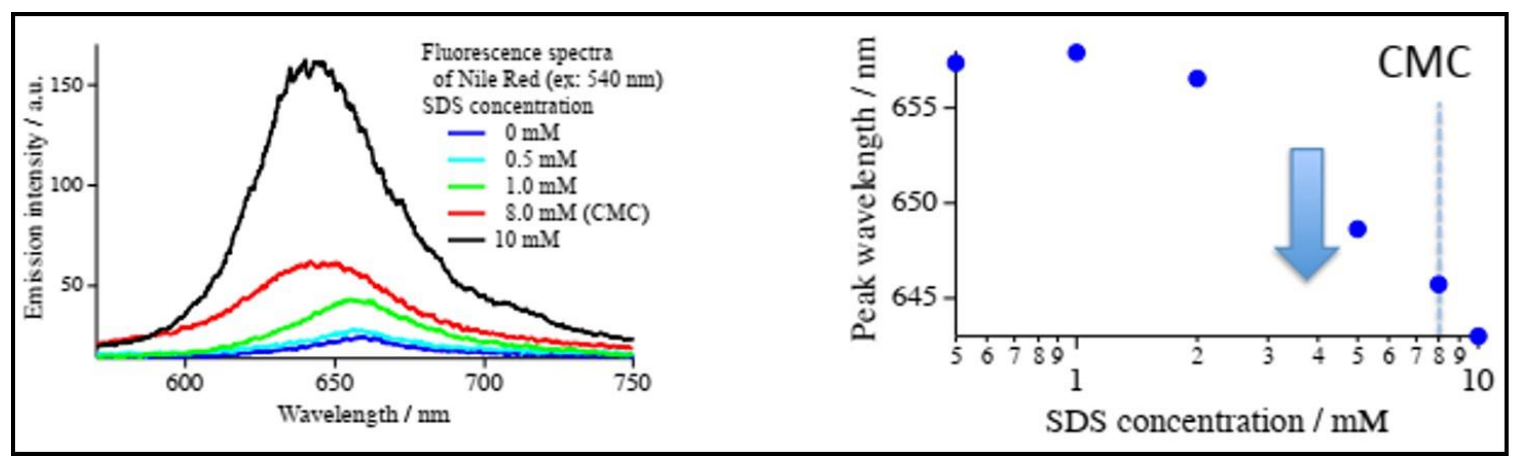

Figure 5. a) shows the fluorescence spectra of Nile Red (Ex. $540 \mathrm{~nm})$ with various SDS concentrations $(0 \mathrm{mM}-10 \mathrm{mM})$. b) shows fluorescence peak wavelength as a function of SDS concentrations

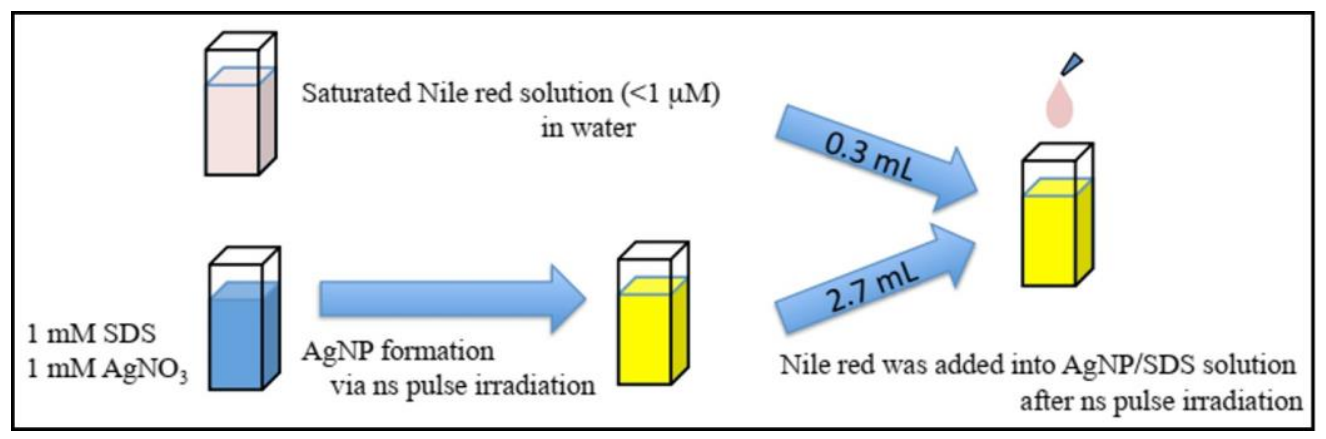

Figure 6. Experimental setup for Nile Red experimental proceedure

\subsection{Fluorescence spectral changes upon NP formation}

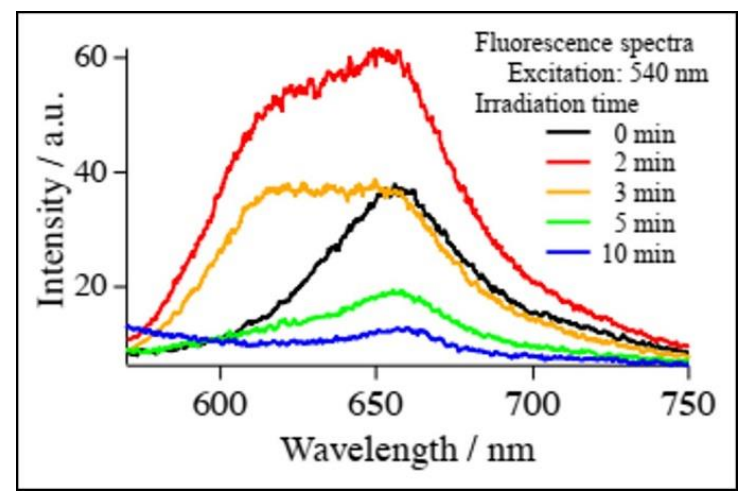

Figure 7. shows the fluorescence spectra of Nile Red (Ex. $540 \mathrm{~nm}$ ) with AgNPs formation in the presence of SDS after pulsed laser irrediation at various time
Figure 7 displays the spectra for Nile Red fluorescence (Ex. $540 \mathrm{~nm}$ ) in AgNP formation following pulsed laser irradiation at different time intervals (varies from 0-10 min) in the presence of SDS. It was noticed that without laser irradiation, an emission peak was at $\sim 655 \mathrm{~nm}$. However, after 2, 3 min irradiation, emission at $\sim 620 \mathrm{~nm}$ was also observed, indicating a hydrophobic region was formed in solution after $\mathrm{AgNP}$ formation. The emission intensity also increased after 2, 3 min irradiation. This result also implies hydrophobic region formation. SDS aggregation upon AgNP formation. With longer laser irradiation, broader emission was still observed, but the intensity became lower. It could be emission quenching at the AgNP surface, or AgNPs prevents excitation light penetration.

\subsection{Model for AgNPs formation with SDS}

The maximum production of NSs is shown as a function of 
the concentration of SDS in Figure 8. Since the SDS CMC is known to be $8.0 \times 10^{-3} \mathrm{M}$, even with 10 times lower than CMC is explained as critical growth concentration (CGC), it has supported the NS formation. The lowest limit of the SDS concentration at which the NSs would start to grow fell in the range between $5 \times 10^{-4}$ and $6 \times 10^{-4} \mathrm{M}$. We are well aware that even below the CMC value of SDS support few aggregates formation. However, with the concentration of $5 \times 10^{-4} \mathrm{M}, 30 \%$ of SDS would form antiparallel dimers, and the others are present in the form of free monomers in an aqueous solution $[65,66]$. SDS aggregates in solution are thus unlikely to act as a "template" for NSs. The interaction between silver NS surfaces and SDS molecules, as described above, should be explained to clarify the role of SDS in the growth of NS at this low concentration [67]. When the SDS concentration was lower than CGC, the SDS adsorbed amount on AgNPs was too small to keep AgNP stable. However, When the SDS concentration was higher than CGC, SDS molecules were adsorbed onto AgNPs produced and formed hemi-micelle structures. Even though there are no micelle structures in the solution before AgNP formation. The amount of SDS adsorbed on AgNPs is large enough to keep AgNP stable. It has been reported that SDSs adsorbed onto a charged surface via Coulombic force make aggregates, hemi-micelles, on the surface by the interaction between alkyl chains even below the CMC. The threshold concentration is known as Critical Hemimicelle concentration (CHMC). It is therefore concluded that the AgNPs growth process can be accelerated by fully overlaying positively charged silver surfaces and by neutralizing adsorption of SDS monolayers [68, 69].

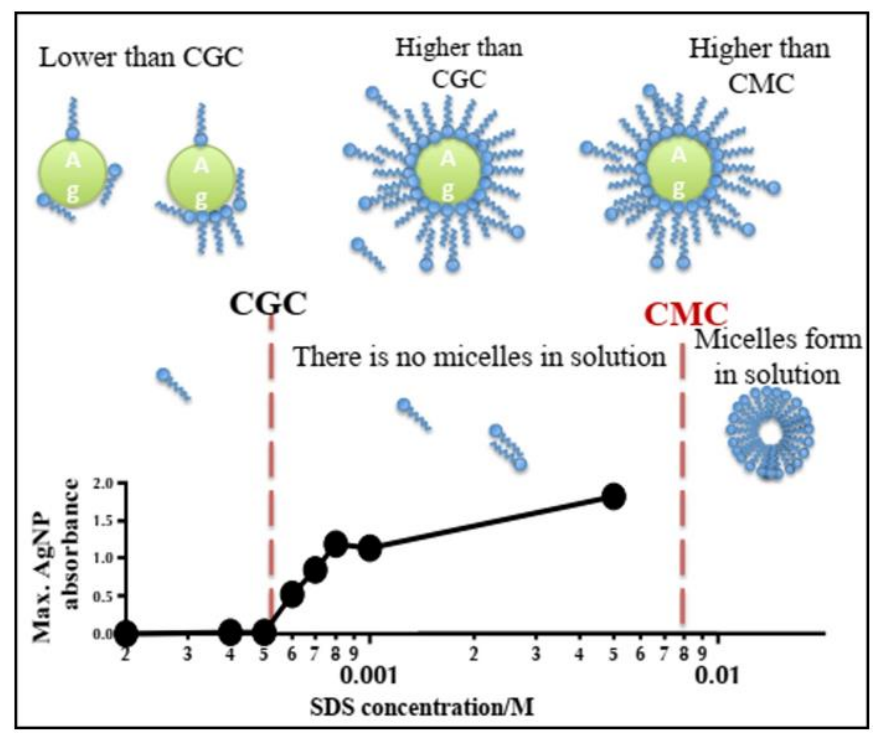

Figure 8. Shows a plot of the maximum yield of NSs as a function of SDS concentration. Each step for the growth process for AgNPs are shown at lower and higher critical growth concentration (CGC)

\section{CONCLUSION}

In this research, the impact of various additives on the mechanism of AgNPs formation was studied. AgNPs were synthesized as a result of photo-reduction of silver ions in an aqueous solution containing surfactants. The concentration dependence of AgNP formation indicates that the stabilization is a result of dynamic equilibrium between free SDS and SDS adsorbed on AgNPs. These findings open a new window for the regulation of the structure and growth process and suggest that various additives influence the shape and the size of NPs. The hydrocarbon chain influenced the growth process and showed that the hydrocarbon chain $<10$ carbon atoms such as SMS, SOS did not form the CGC and had a little impact on the growth process. However, the CGC observed with hydrocarbon chain > 10 carbon atoms like AOT, SDS. The NPS started to develop and regulate the size and shape of the photoproduct at the lowest limits. Fluorescence experiments implied that hemi-micelle formed upon AgNP formation by laser irradiation. According to the best of our knowledge, this is the first time to discuss the potential effect of each additive directly using light as a reducing agent.

\section{ACKNOWLEDGMENT}

Dr. Umair Yaqub Qazi extends his appreciation to the Deanship of Scientific Research, University of Hafr Al Batin, for funding this work through the research group project No. G-122-2020. Dr. Umair Yaqub Qazi is also thankful for Prof. Hiroshi Fukumura and Dr. Shinji Kajimoto for partial laboratory instruments usage and technical assistance to complete this research work at Tohoku University.

\section{REFERENCES}

[1] Javaid, R.; Qazi, U. Y. Catalytic Oxidation Process for the Degradation of Synthetic Dyes: An Overview. International Journal of Environmental Research and Public Health 2019, $16 \quad$ (11). https://doi.org/10.3390/ijerph16112066.

[2] Javaid, R.; Qazi, U. Y.; Kawasaki, S.-I. Efficient and Continuous Decomposition of Hydrogen Peroxide Using a Silica Capillary Coated with a Thin Palladium or Platinum Layer. BCSJ 2015, 88 (7), 976-980. https://doi.org/10.1246/bcsj.20150052.

[3] Javaid, R.; Qazi, U. Y.; Kawasaki, S.-I. Highly Efficient Decomposition of Remazol Brilliant Blue R Using Tubular Reactor Coated with Thin Layer of PdO. Journal of Environmental Management 2016, 180 , $551-556$. https://doi.org/10.1016/j.jenvman.2016.05.075.

[4] Afzal, A.; Mujahid, A.; Iqbal, N.; Javaid, R.; Qazi, U. Y. Enhanced High-Temperature $\left(600{ }^{\circ} \mathrm{C}\right)$ NO2 Response of ZnFe2O4 Nanoparticle-Based Exhaust Gas Sensors. Nanomaterials 2020, 10 (11), 2133. https://doi.org/10.3390/nano10112133.

[5] Qazi, U. Y.; Javaid, R.; Tahir, N.; Jamil, A.; Afzal, A. Design of Advanced Self-Supported Electrode by Surface Modification of Copper Foam with Transition Metals for Efficient Hydrogen Evolution Reaction. International Journal of Hydrogen Energy 2020. https://doi.org/10.1016/j.ijhydene.2020.09.026.

[6] A Review on Metal Nanostructures: Preparation Methods and Their Potential Applications https://www.scirp.org/journal/paperinformation.aspx ?paperid=63388 $($ accessed Nov 9, 2020).

[7] Niemeyer, C. M. Nanoparticles, Proteins, and Nucleic Acids: Biotechnology Meets Materials Science. Angewandte Chemie International Edition 2001, $40 \quad$ (22), $4128-4158$. 
Influence of Surfactant Additives on Photochemical Synthesized Silver Nanoparticles using UV Pulsed Laser Irradiations in Aqueous Silver Nitrate Solution / J. New Mat. Electrochem. Systems

https://doi.org/10.1002/1521-

3773(20011119)40:22<4128::AID-

ANIE4128>3.0.CO;2-S.

[8] Zhao, J.; Zhang, Y.; Huang, Y.; Xie, J.; Zhao, X.; Li, C.; Qu, J.; Zhang, Q.; Sun, J.; He, B.; Li, Q.; Lu, C.; $\mathrm{Xu}, \mathrm{X}$; Lu, W.; Li, L.; Yao, Y. 3D Printing Fiber Electrodes for an All-Fiber Integrated Electronic Device via Hybridization of an Asymmetric Supercapacitor and a Temperature Sensor. Advanced Science 2018, 5 (11), 1801114. https://doi.org/10.1002/advs.201801114.

[9] Yaqub Qazi, U.; Shervani, Z.; Javaid, R. Green Synthesis of Silver Nanoparticles by Pulsed Laser Irradiation: Effect of Hydrophilicity of Dispersing Agents on Size of Particles. Front Nanosci Nanotech 2018, 4 (1). https://doi.org/10.15761/FNN.1000163.

[10]Zou, H.-H.; Yuan, C.-Z.; Zou, H.-Y.; Cheang, T.-Y.; Zhao, S.-J.; Qazi, U. Y.; Zhong, S.-L.; Wang, L.; Xu, A.-W. Bimetallic Phosphide Hollow Nanocubes Derived from a Prussian-Blue-Analog Used as HighPerformance Catalysts for the Oxygen Evolution Reaction. Catal. Sci. Technol. 2017, 7 (7), 15491555. https://doi.org/10.1039/C7CY00035A.

[11] One-Step Growth of Iron-Nickel Bimetallic Nanoparticles on FeNi Alloy Foils: Highly Efficient Advanced Electrodes for the Oxygen Evolution Reaction | ACS Applied Materials \& Interfaces https://pubs.acs.org/doi/abs/10.1021/acsami.7b0892 2 (accessed Nov 9, 2020).

[12] One-Step In Situ Growth of Iron-Nickel Sulfide Nanosheets on FeNi Alloy Foils: High-Performance and Self-Supported Electrodes for Water Oxidation Yuan - 2017 - Small - Wiley Online Library https://onlinelibrary.wiley.com/doi/abs/10.1002/smll .201604161 (accessed Nov 9, 2020).

[13] Thakkar, K. N.; Mhatre, S. S.; Parikh, R. Y. Biological Synthesis of Metallic Nanoparticles. Nanomedicine: Nanotechnology, Biology and Medicine 2010, $6 \quad$ (2), 257-262. https://doi.org/10.1016/j.nano.2009.07.002.

[14] Shameli, K.; Bin Ahmad, M.; Jazayeri, S. D.; Sedaghat, S.; Shabanzadeh, P.; Jahangirian, H.; Mahdavi, M.; Abdollahi, Y. Synthesis and Characterization of Polyethylene Glycol Mediated Silver Nanoparticles by the Green Method. International Journal of Molecular Sciences 2012, 13 (6), $6639-6650$. https://doi.org/10.3390/ijms13066639.

[15] Kouvaris, P.; Delimitis, A.; Zaspalis, V.; Papadopoulos, D.; Tsipas, S. A.; Michailidis, N. Green Synthesis and Characterization of Silver Nanoparticles Produced Using Arbutus Unedo Leaf Extract. Materials Letters 2012, 76, 18-20. https://doi.org/10.1016/j.matlet.2012.02.025.

[16]Bifunctional 2D Cd(II)-Based Metal-Organic Framework as Efficient Heterogeneous Catalyst for the Formation of $\mathrm{C}-\mathrm{C}$ Bond | Crystal Growth \& Design

https://pubs.acs.org/doi/abs/10.1021/acs.cgd.7b0172 8 (accessed Nov 9, 2020).

[17] Fatima, N.; Qazi, U. Y.; Mansha, A.; Bhatti, I. A.; Javaid, R.; Abbas, Q.; Nadeem, N.; Rehan, Z. A.; Noreen, S.; Zahid, M. Recent Developments for Antimicrobial Applications of Graphene-Based
Polymeric Composites: A Review. Journal of Industrial and Engineering Chemistry 2021. https://doi.org/10.1016/j.jiec.2021.04.050.

[18] Javaid, R.; Qazi, U. Y.; Ikhlaq, A.; Zahid, M.; Alazmi, A. Subcritical and Supercritical Water Oxidation for Dye Decomposition. Journal of Environmental Management 2021, 290, 112605. https://doi.org/10.1016/j.jenvman.2021.112605.

[19] Qazi, U. Y.; Javaid, R.; Zahid, M.; Tahir, N.; Afzal, A.; Lin, X.-M. Bimetallic NiCo-NiCoO2 NanoHeterostructures Embedded on Copper Foam as a Self-Supported Bifunctional Electrode for Water Oxidation and Hydrogen Production in Alkaline Media. International Journal of Hydrogen Energy 2021, $46 \quad$ (36), 18936-18948. https://doi.org/10.1016/j.ijhydene.2021.03.046.

[20] Ikhlaq, A.; Fatima, R.; Qazi, U. Y.; Javaid, R.; Akram, A.; Ibn Shamsah, S.; Qi, F. Combined Iron-Loaded Zeolites and Ozone-Based Process for the Purification of Drinking Water in a Novel Hybrid Reactor: Removal of Faecal Coliforms and Arsenic. $\begin{array}{llll}\text { Catalysts } & \mathbf{2 0 2 1}, & 11 & \text { (3), }\end{array} 373$. https://doi.org/10.3390/catal11030373.

[21] Tabasum, A.; Alghuthaymi, M.; Qazi, U. Y.; Shahid, I.; Abbas, Q.; Javaid, R.; Nadeem, N.; Zahid, M. UVAccelerated Photocatalytic Degradation of Pesticide over Magnetite and Cobalt Ferrite Decorated Graphene Oxide Composite. Plants 2021, 10 (1), 6. https://doi.org/10.3390/plants10010006.

[22] Javaid, R.; Nanba, T. Effect of Reaction Conditions and Surface Characteristics of $\mathrm{Ru} / \mathrm{CeO} 2$ on Catalytic Performance for Ammonia Synthesis as a Clean Fuel. International Journal of Hydrogen Energy 2020. https://doi.org/10.1016/j.ijhydene.2020.07.222.

[23] Afzal, A.; Abuilaiwi, F. A.; Javaid, R.; Ali, F.; Habib, A. Solid-State Synthesis of Heterogeneous $\mathrm{Ni0.5Cu0.5-XZnxFe2O4}$ Spinel Oxides with Controlled Morphology and Tunable Dielectric Properties. J Mater Sci: Mater Electron 2020, 31 (17), 14261-14270. https://doi.org/10.1007/s10854-02003982-8.

[24] Javaid, R.; Aoki, Y.; Nanba, T. Highly Efficient $\mathrm{Ru} / \mathrm{MgO}-\mathrm{Er} 2 \mathrm{O} 3$ Catalysts for Ammonia Synthesis. Journal of Physics and Chemistry of Solids 2020, 146, 109570. https://doi.org/10.1016/j.jpcs.2020.109570.

[25] Javaid, R.; Nanba, T. MgFe2O4-Supported Ru Catalyst for Ammonia Synthesis: Promotive Effect of Chlorine. ChemistrySelect 2020, 5 (14), 4312-4315. https://doi.org/10.1002/slct.202000883.

[26] Dimitriou, P.; Javaid, R. A Review of Ammonia as a Compression Ignition Engine Fuel. International Journal of Hydrogen Energy 2020, 45 (11), 70987118. https://doi.org/10.1016/j.ijhydene.2019.12.209.

[27] Javaid, R.; Matsumoto, H.; Nanba, T. Influence of Reaction Conditions and Promoting Role of Ammonia Produced at Higher Temperature Conditions in Its Synthesis Process over Cs- $\mathrm{Ru} / \mathrm{MgO}$ Catalyst. ChemistrySelect 2019, 4 (7), 2218-2224. https://doi.org/10.1002/slct.201803813.

[28] Javaid, R.; Urata, K.; Furukawa, S.; Komatsu, T. Factors Affecting Coke Formation on H-ZSM-5 in Naphtha Cracking. Applied Catalysis A: General 2015, 491, 100-105. https://doi.org/10.1016/j.apcata.2014.12.002. 
[29] Javaid, R.; Kawasaki, S.; Ookawara, R.; Sato, K.; Nishioka, M.; Suzuki, A.; Suzuki, T. M. Continuous Dehydrogenation of Aqueous Formic Acid under Sub-Critical Conditions by Use of Hollow Tubular Reactor Coated with Thin Palladium Oxide Layer. Journal of Chemical Engineering of Japan 2013, 46 (11), 751-758. https://doi.org/10.1252/jcej.13we184.

[30] Javaid, R.; Kawasaki, S.; Suzuki, A.; Suzuki, T. M. Simple and Rapid Hydrogenation of P-Nitrophenol with Aqueous Formic Acid in Catalytic Flow Reactors. Beilstein J. Org. Chem. 2013, 9 (1), 11561163. https://doi.org/10.3762/bjoc.9.129.

[31] Javaid, R.; Kawanami, H.; Chatterjee, M.; Ishizaka, T.; Suzuki, A.; Suzuki, T. M. Sonogashira C-C Coupling Reaction in Water Using Tubular Reactors with Catalytic Metal Inner Surface. Chemical Engineering Journal 2011, 167 (2), 431-435. https://doi.org/10.1016/j.cej.2010.08.080.

[32] Javaid, R.; Kawanami, H.; Chatterjee, M.; Ishizaka, T.; Suzuki, A.; Suzuki, T. M. Fabrication of Microtubular Reactors Coated with Thin Catalytic Layer $(\mathrm{M}=\mathrm{Pd}, \mathrm{Pd}-\mathrm{Cu}, \mathrm{Pt}, \mathrm{Rh}, \mathrm{Au})$. Catalysis Communications 2010, 11 (14), 1160-1164. https://doi.org/10.1016/j.catcom.2010.05.018.

[33] Javaid, R.; Tanaka, D. A. P.; Kawanami, H.; Suzuki, T. M. Silica Capillary with Thin Metal (Pd and Pt) Inner Wall: Application to Continuous Decomposition of Hydrogen Peroxide. Chem. Lett. 2009, 38 (2), 146-147. https://doi.org/10.1246/cl.2009.146.

[34] Gurunathan, S.; Kalishwaralal, K.; Vaidyanathan, R.; Venkataraman, D.; Pandian, S. R. K.; Muniyandi, J.; Hariharan, N.; Eom, S. H. Biosynthesis, Purification and Characterization of Silver Nanoparticles Using Escherichia Coli. Colloids and Surfaces B: Biointerfaces 2009, 74 (1), 328-335. https://doi.org/10.1016/j.colsurfb.2009.07.048.

[35] Sánchez-López, E.; Gomes, D.; Esteruelas, G.; Bonilla, L.; Lopez-Machado, A. L.; Galindo, R.; Cano, A.; Espina, M.; Ettcheto, M.; Camins, A.; Silva, A. M.; Durazzo, A.; Santini, A.; Garcia, M. L.; Souto, E. B. Metal-Based Nanoparticles as Antimicrobial Agents: An Overview. Nanomaterials 2020, 10 (2), 292. https://doi.org/10.3390/nano10020292.

[36] COVID-19 Vaccine https://www.scirp.org/html/201950510_102875.htm (accessed Nov 9, 2020).

[37] Shervani, Z.; Khan, I.; Khan, T.; Qazi, U. Y. World's Fastest Supercomputer Picks COVID-19 Drug. Advances in Infectious Diseases 2020, 10 (03), 211. https://doi.org/10.4236/aid.2020.103021.

[38] Shervani, Z.; Khan, I.; Qazi, U. Y. SARS-Cov-2 Delayed Tokyo 2020 Olympics: Very Recent Advances in COVID-19 Detection, Treatment, and Vaccine Development Useful Conducting the Games in 2021. Advances in Infectious Diseases 2020, 10 (03), 56. https://doi.org/10.4236/aid.2020.103007.

[39] Shah, S. I. A.; Iqbal, S.; Sikandar, M. Z.; Qazi, U. Y.; Haq, I. Serum Vitamin D and Cardiometabolic Markers: A Comparative Study in Adult Men Based on Body Mass Index. imjm 2021, 20 (2). https://doi.org/10.31436/imjm.v20i2.1640.

[40] Cd-Gd-doped nickel spinel ferrite nanoparticles and their nanocomposites with reduced graphene oxide for catalysis and antibacterial activity studies -
ScienceDirect

https://www.sciencedirect.com/science/article/pii/S0

27288422033683X (accessed Jun 1, 2021).

[41] Silver Nanoparticles Formation by Nanosecond Pulsed Laser Irradiation in an Aqueous Solution of Silver Nitrate; Effect of Sodium bis (2-ethyl hexyl) Sulfosuccinate | IIETA https://www.iieta.org/journals/jnmes/paper/10.1444 7/jnmes.v24i1.a07 (accessed Jun 1, 2021).

[42] Shah, S. I. A.; Sikandar, M. Z.; Qazi, Y.; Haq, I. Myocardial Infarction in Young People: Anxiety in the Lead? 2021, 7.

[43] Shervani, Z.; Khan, I.; Siddiqui, N. Y.; Khan, T.; Qazi, U. Y. Risk of SARS-CoV-2 Transmission from Humans to Pets and Vice Versa. European Journal of Medical and Health Sciences 2021, 3 (1), 34-38. https://doi.org/10.24018/ejmed.2021.3.1.684.

[44] Shah, S. I. A.; Sikandar, M. Z.; Qazi, U. Y. Comparative Assessment of Vitamin D and Parathyroid Hormone as Risk Factors of Myocardial Infarction and Their Correlation with Lipid Profile. 2021, 7.

[45] Shervani, Z.; Khan, I.; Siddiqui, N. Y.; Khan, T.; Qazi, U. Y. Viability of SARS-CoV-2 and Sanitization Methods. European Journal of Medical and Health Sciences 2021, 3 (1), 22-27. https://doi.org/10.24018/ejmed.2021.3.1.665.

[46] Abuilaiwi, F.; Awais, M.; Qazi, U. Y.; Afzal, A. Al3+ Doping Reduces the Electron/Hole Recombination in Photoluminescent Copper Ferrite ( $\mathrm{CuFe} 2-x \mathrm{AlxO} 4)$ Nanocrystallites. Boletín de la Sociedad Española de $\begin{array}{llll}\text { Cerámica } & y & \text { Vidrio } & \end{array}$ https://doi.org/10.1016/j.bsecv.2020.11.007.

[47] Treatment of leachate through constructed wetlands using Typha angustifolia in combination with catalytic ozonation on Fe-zeolite A: International Journal of Phytoremediation: Vol 0 , No 0 https://www.tandfonline.com/doi/abs/10.1080/1522 6514.2020.1858753 (accessed Jun 1, 2021).

[48]Zeb, A.; Sahar, S.; Qazi, U. Y.; Odda, A. H.; Ullah, N.; Liu, Y.-N.; Qazi, I. A.; Xu, A.-W. Intrinsic Peroxidase-like Activity and Enhanced Photo-Fenton Reactivity of Iron-Substituted Polyoxometallate Nanostructures. Dalton Trans. 2018, 47 (21), 73447352. https://doi.org/10.1039/C8DT01146J.

[49] Catalytic Conversion of Biomass into Hydrocarbons over Noble-Metal-Free VO-Substituted Potassium Salt of Phosphotungstic Acid - Imran - 2017 ChemistrySelect - Wiley Online Library https://chemistryeurope.onlinelibrary.wiley.com/doi/abs/10.1002/slct .201702088 (accessed Nov 9, 2020).

[50] Ullah, N.; Imran, M.; Liang, K.; Yuan, C.-Z.; Zeb, A. Jiang, N.; Qazi, U. Y.; Sahar, S.; Xu, A.-W. Highly Dispersed Ultra-Small Pd Nanoparticles on Gadolinium Hydroxide Nanorods for Efficient Hydrogenation Reactions. Nanoscale 2017, 9 (36), 13800-13807. https://doi.org/10.1039/C7NR05096H.

[51] Formation and Growth of Silver Nanocubes upon Nanosecond Pulsed Laser Irradiation: Effects of Laser Intensity and Irradiation Time https://www.scirp.org/journal/paperinformation.aspx ?paperid=80151 (accessed Nov 9, 2020). 
Influence of Surfactant Additives on Photochemical Synthesized Silver Nanoparticles using UV Pulsed Laser Irradiations in Aqueous Silver Nitrate Solution / J. New Mat. Electrochem. Systems

[52] Park, C. M.; Wang, D.; Han, J.; Heo, J.; Su, C. Evaluation of the Colloidal Stability and Adsorption Performance of Reduced Graphene Oxide-Elemental Silver/Magnetite Nanohybrids for Selected Toxic Heavy Metals in Aqueous Solutions. Applied Surface Science 2019, 471, 8-17. https://doi.org/10.1016/j.apsusc.2018.11.240.

[53] Jamkhande, P. G.; Ghule, N. W.; Bamer, A. H.; Kalaskar, M. G. Metal Nanoparticles Synthesis: An Overview on Methods of Preparation, Advantages and Disadvantages, and Applications. Journal of Drug Delivery Science and Technology 2019, 53, 101174. https://doi.org/10.1016/j.jddst.2019.101174.

[54] Wang, Y.; O’Connor, D.; Shen, Z.; Lo, I. M. C.; Tsang, D. C. W.; Pehkonen, S.; Pu, S.; Hou, D. Green Synthesis of Nanoparticles for the Remediation of Contaminated Waters and Soils: Constituents, Synthesizing Methods, and Influencing Factors. Journal of Cleaner Production 2019, 226, 540-549. https://doi.org/10.1016/j.jclepro.2019.04.128.

[55] Yaqoob, A. A.; Umar, K.; Ibrahim, M. N. M. Silver Nanoparticles: Various Methods of Synthesis, Size Affecting Factors and Their Potential Applications-a Review. Appl Nanosci 2020, 10 (5), 1369-1378. https://doi.org/10.1007/s13204-020-01318-w.

[56] Qazi, U. Y.; Kajimoto, S.; Fukumura, H. Effect of Sodium Dodecyl Sulfate on the Formation of Silver Nanoparticles by Biphotonic Reduction of Silver Nitrate in Water. Chem. Lett. 2014, 43 (11), 16931695. https://doi.org/10.1246/cl.140617.

[57] Qazi, U. Y. Surfactant Effect on Nanoparticle Formation by Biphotonic Reduction of Silver Ions in Aqueous Solution. 2014, 114.

[58] Aniansson, E. A. G.; Wall, S. N.; Almgren, M.; Hoffmann, H.; Kielmann, I.; Ulbricht, W.; Zana, R.; Lang, J.; Tondre, C. Theory of the Kinetics of Micellar Equilibria and Quantitative Interpretation of Chemical Relaxation Studies of Micellar Solutions of Ionic Surfactants. J. Phys. Chem. 1976, 80 (9), 905922. https://doi.org/10.1021/j100550a001.

[59] Shirahama, K.; Kashiwabara, T. The CMCDecreasing Effects of Some Added Alcohols on the Aqueous Sodium Dodecyl Sulfate Solutions. Journal of Colloid and Interface Science 1971, 36 (1), 65-70. https://doi.org/10.1016/0021-9797(71)90240-2.

[60] Langille, M. R.; Personick, M. L.; Mirkin, C. A. Plasmon-Mediated Syntheses of Metallic Nanostructures. Angew Chem Int Ed Engl 2013, 52 (52), $13910-13940$ https://doi.org/10.1002/anie.201301875.

[61] Stamplecoskie, K. G.; Scaiano, J. C. Silver as an Example of the Applications of Photochemistry to the Synthesis and Uses of Nanomaterials $\dagger, \$$. Photochemistry and Photobiology 2012, 88 (4), 762768. https://doi.org/10.1111/j.17511097.2012.01103.x.

[62] Size, Shape, Stability, and Color of Plasmonic Silver Nanoparticles | The Journal of Physical Chemistry C https://pubs.acs.org/doi/10.1021/jp5018168 (accessed Nov 9, 2020).

[63] Nagarajan, R.; Ruckenstein, E. Theory of surfactant self-assembly: a predictive molecular thermodynamic approach https://pubs.acs.org/doi/pdf/10.1021/la00060a012 